\title{
ANALYSIS OF APPLICABILITY OF COMPOSITE MATERIALS IN SUPPORTING CONSTRUCTIONS OF BRIDGES
}

\author{
Viktor Shendrik', Aleksandr Kvitko² \\ 1,2 Saint Petersburg State University of Architecture and Civil Engineering \\ Vtoraja Krasnoarmejskja ul. 4, St. Petersburg, Russia \\ 1 vicinshendrik@yandex.ru, ${ }^{2}$ kvitko.67.67@mail.ru
}

\begin{abstract}
In this paper we substantiated the necessity for application of composite materials in bridge supporting constructions. We listed the disadvantages of traditional materials and advantages of innovative ones. We also considered basic loads and effects on bridge supporting constructions which are to be sustained by structures made from the applied materials. We described the structure of composite materials, methods of manufacturing them as well as the factors influencing the characteristics of constructions made of them. We selected the type of bridge supporting constructions suitable for application of the new materials. We provided the results of experiments under poles made of polymer materials conducted by our foreign colleagues. We presented the information about testing of screw piles made of composite materials.
\end{abstract}

Keywords: bridgework, supporting constructions, composite materials, advantages and disadvantages of composite materials, experimental studies.

\section{Introduction}

Due to the successful use of composite materials in various industries, such as aerospace and defense industries, engineers' wish to use materials with beneficial properties is quite reasonable. New progressive materials are used in construction as well. They are used, for example in works at the facade of buildings for heat insulation, in laying utilities, and generally in non structural elements. However, it is obvious that the potential for development of composite materials allows applying them in load-carrying structures as well. The perspective direction for their use is manufacturing of bridge pile piers. Composite materials have low weight, they are lighter than steel by several times. They are factory fabricated and can be easily framed in the shortest possible time. The cost of mass-produced budget-priced composite materials, for example, made of fiberglass is close to the cost of metal.

Steel parts have been employed in bridge engineering for a long time and significantly excel reinforced concrete in some quality characteristics, but they are much more expensive; this is the main reason that steel is not generally adopted to replace reinforced concrete structures.
That is why engineers search for an alternative, which will not be much more expensive than traditional reinforced concrete and will not demand high cost for maintenance as steel construction. New materials should have the characteristics which are as good as those of reinforced concrete and steel when they are traditionally applied for erection of bridge piers. Composite materials cannot completely replace reinforced concrete, but the units made from them should be capable of withstanding exactly those types of load, which affect the piers of a bridge. The characteristics of various composite materials can significantly differ depending on the way of their manufacturing and of the employed materials. Manufacturers should aim at the necessary characteristics knowing beforehand their final use. If a change is introduced even in one of the manufacturing parameters in the technology, this will result in a different material. Thus, it is possible to produce with such changes from a composite material which has already been manufactured before a new one with the characteristics necessary for a particular case. Structural elements made of these materials may be used in the 
construction of mid-piers of bridges. Further, in this article experimental studies conducted by different authors are presented. From our point of view, it is quite possible to use composite materials in the constructions of mid-piers of small-size bridges supported by piles.

The aim of this study is to examine the reliability of bridge supporting constructions made of composite materials. Structurally this study includes experimental investigation of models in order to examine loads and effects, working out of recommendations for testing of supporting constructions made of composite materials. The characteristics obtained in these experiments will allow deciding whether to adapt the existing method of calculation, such as that of reinforced concrete envelope, for composite materials or to work out a new method of calculation. Since there are no prototype bridges with composite piers, this is a scientifically novel study. We expect that, as a result of this study, a useful model patent will be worked out and this model will be used in designing a prototype application.

Composites can be more economically viable than traditional materials, because during their production several substances are used and the final product has all the advantages of each composing substance (Solntsev, 2007). The components of composites vary greatly from each other by their characteristics.

Structurally, the mid-pier consists of a foundation, a pier body and a cap with bed blocks on which bearings are mounted. In pile pier construction the piles act as both a foundation and a body joined together by cap at the top. These piles as well as other parts can be made of composite materials (Figure 1), which is the objective of the present study.

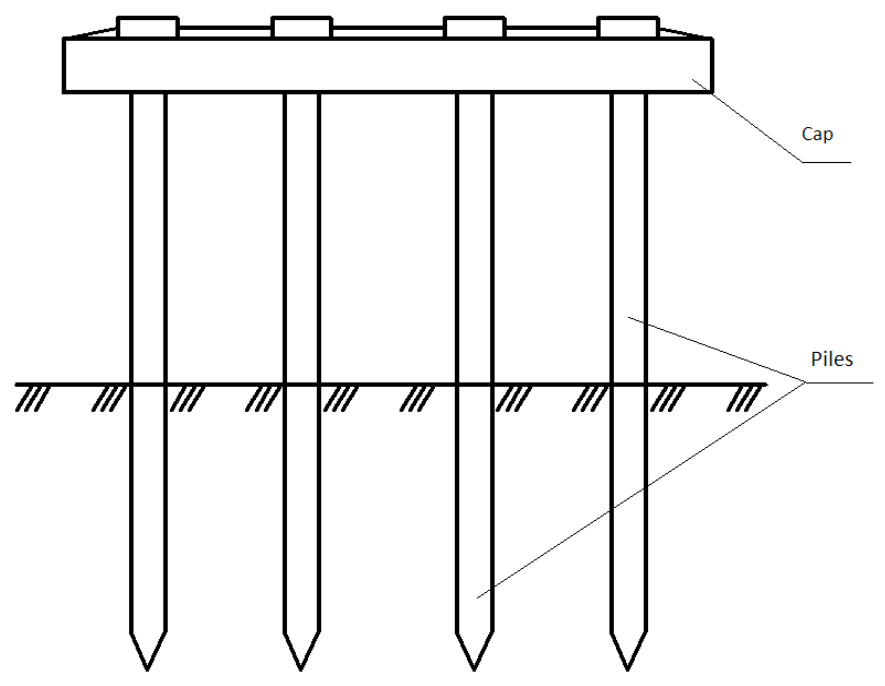

Figure 1. Drawing of pile-type pier

Such piles for piers without grillage are relevant to bridgeworks built upon dry valleys as well as for the elevated roads and viaducts. These structures are very simple to erect. Their peculiarity to offset corrosive environments will be very useful here. Although, inevitable difficulties must be overcome when combining reinforced concrete cap and piles made of composite material. Then there is a possibility for structural support of the span by means of cap plates of pile or pole supporting structures. It will be an economically viable solution to use composite materials for such supporting structures (Salamakhin, 2014). Pole piers have been constructed in our country since late 1960s; the reinforced concrete hollow shell piles with diameter of $0.8 \mathrm{~m}$ to $1.0 \mathrm{~m}$ made of circular sections up to $8 \mathrm{~m}$ in length with a wall thickness of $10 \mathrm{~cm}$ to $12 \mathrm{~cm}$ were traditionally used. At a later stage, piles with a hollow section having a diameter of $1.6 \mathrm{~m}$ and with $12 \mathrm{~m}$ in length were also used. These hollow section piles were joined by means of flanges connected by bolts. The lower part of these hollow shells was filled with concrete up to $3 \mathrm{~m}$ to ensure their bearing capacity, while the upper inner part of the hollow shells was filled with soil and water-repellent sand to the height of the supposed fluctuation of water horizon in order to eliminate the possibility of pressure break by the freezing water. The advantage of this solution is avoiding the necessity for erection of grillages as well as the reduction of materials consumption (Ivanchev, 2008). However, vertical cracks often appeared before the expiration of the expected working life of piers. It is necessary to thoroughly study the cause for this phenomenon. Making such supporting constructions from composite materials is rational due to their lower weight than reinforced concrete piles and their economical viability. However, prior to using such composite material piers in actual construction they must be theoretically and experimentally checked.

Certain aspects of this issue have been studied by our foreign colleagues. M.A. ElGawady and H.M. Dawood (2012) conducted theoretical computations along with experiment; they studied a finite element three-dimensional numerical model using ABAQUS Standard software, and their results of testing such piers to lateral loads are briefly presented in the next section.

\section{Pile specimens subjected to lateral loading}

According to the initial data, the tests were performed for the piers constructed out of segmental precast concrete filled polymer tubes. Reinforcing steel bars were also placed through channels prepared in advance. Subsequent tests showed that an increase in the pre-stressing force led to an increase in the strength rating. In addition, such parameters as the dimension of the sides, the length of the piers and their cross sectional diameter significantly influence their characteristics.

Lateral load was applied exactly in the middle of $254 \mathrm{~mm}$ cap by a special gear. Thus, the lever arm from foundation to the loading point was equal to $1651 \mathrm{~mm}$. Sample 1 consisted of 1 solid segment of tube, while sample 2 consisted of 4 segments of composite tubes of $381 \mathrm{~m}$ in height filled with concrete (Figure 2).

After such numerical simulations were performed, an actual experiment was also conducted.

A series of tubes with wall thickness of $19 \mathrm{~mm}$, "L" diameter of $1,220 \mathrm{~mm}$ and "S" diameter of $610 \mathrm{~mm}$ were manufactured. Each series included three samples with heights of $3,660 \mathrm{~mm}, 5,490 \mathrm{~mm}$ and $9,150 \mathrm{~mm}$. The tubes were made 


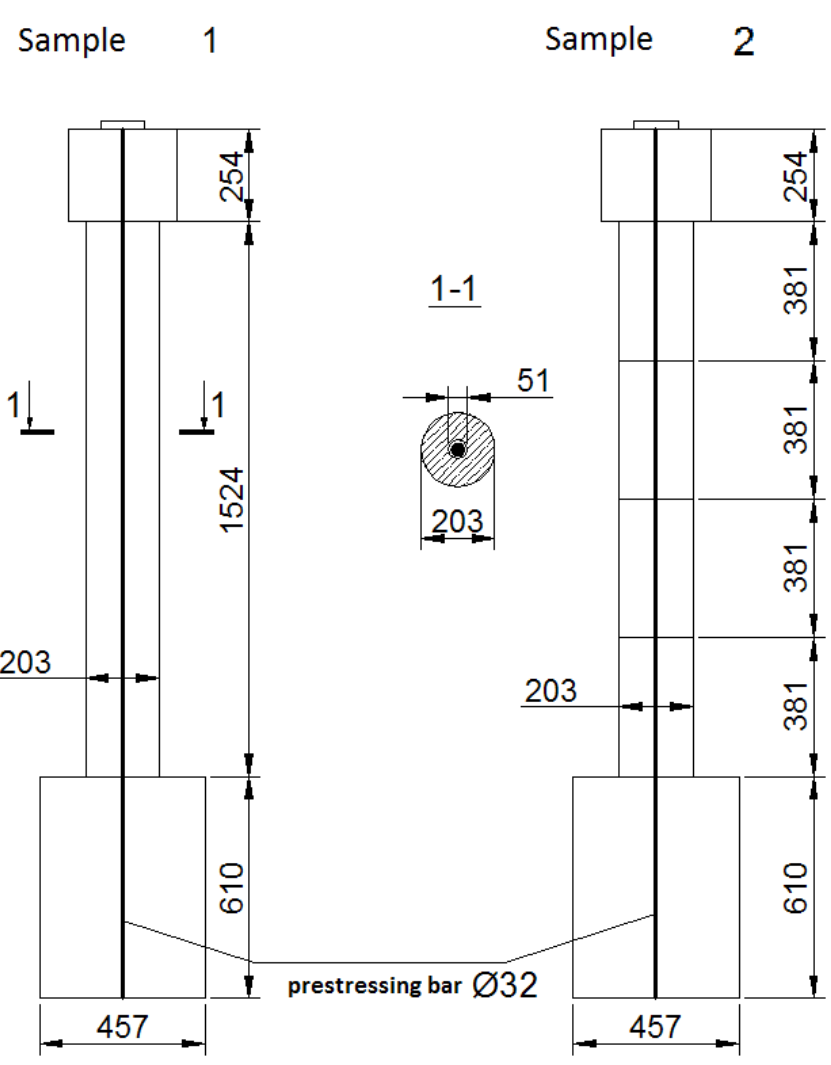

Figure 2. Sample sizes of three-dimensional model (Reproduced with minor modifications by permission of M.A. ElGawady and H.M. Dawood)

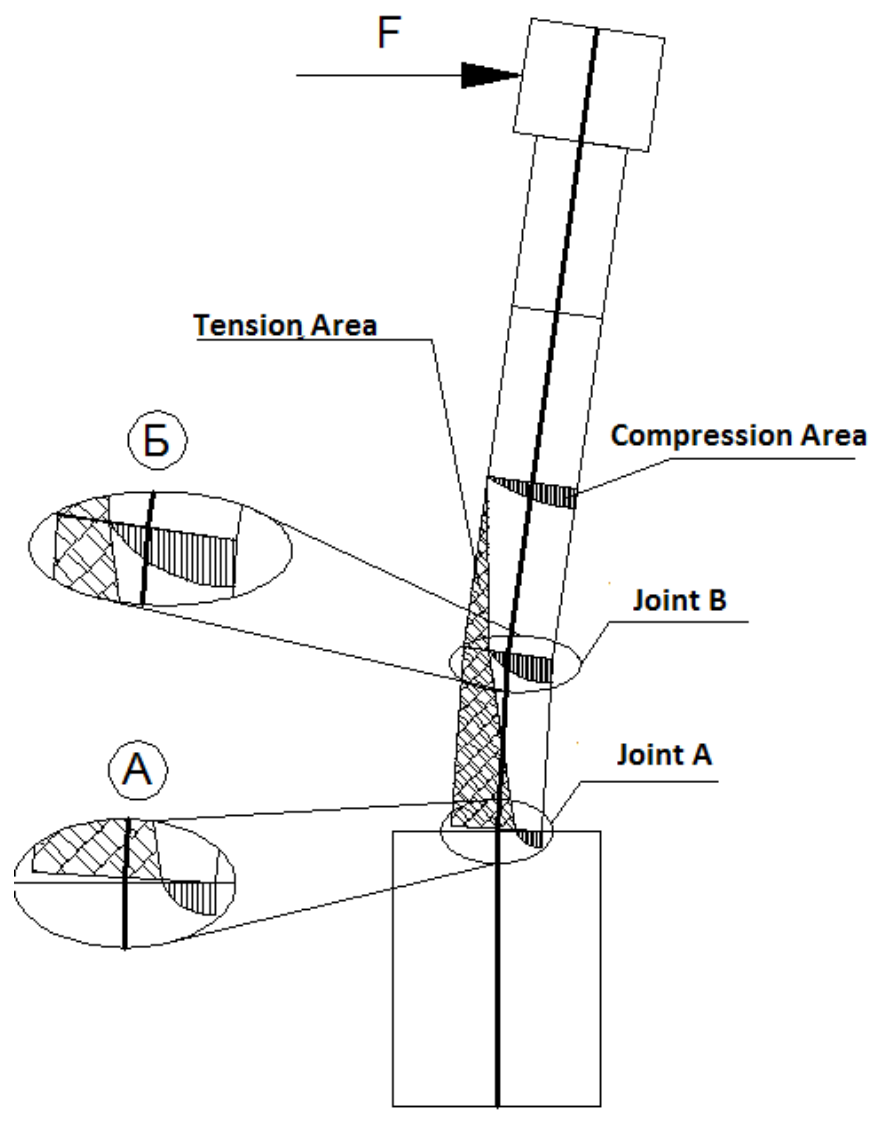

Figure 4. Deformation of pile affected by lateral load (Reproduced with minor modifications by permission of M.A. ElGawady and H.M. Dawood)

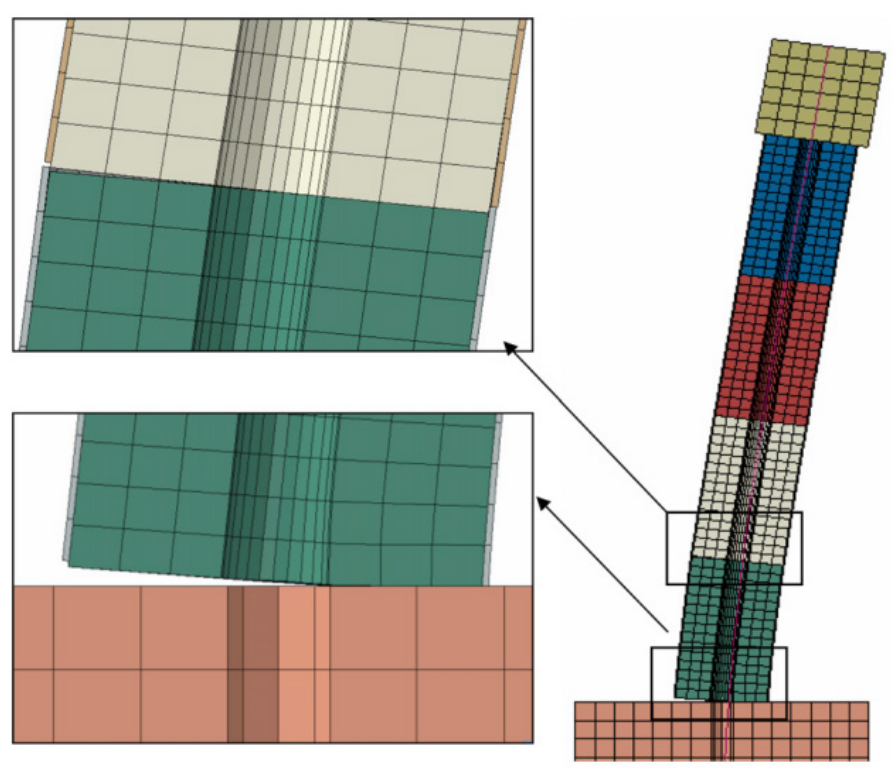

Figure 3. Deformation of sample 2 three-dimensional model (Reproduced by permission of M.A. ElGawady and H.M. Dawood)

by filament-winding technique with $55^{\circ}$ glass fiber orientation with respect to the longitudinal axis of the tube. Each sample was reinforced by $32 \mathrm{~mm}$ post-tensioning bar placed along the whole length of the tube through PVC-channel inside the pier. Two strain gauges were mounted on the bar and were used to monitor the strains in the bar during the posttensioning and tests. The effective strain in the bar after post-tensioning was approximately $165 \mathrm{kN}$ or $30 \%$ of the ultimate strength of the post-tensioning bar (Figure 4). The material properties for the bar were provided by the bar manufacturer (ElGawady and Dawood, 2012).

The bar was rigidly fixed to the foundation embedded in the floor. A U-shaped frame made from three steel $\mathrm{H}$-beams welded to each other was fixed above the bar. 2 horizontal metal cores were positioned between the foundation and the vertical beams of the frame. The bar was slightly shifted from the symmetry axis of the U-shaped frame, and the mechanism for providing load effect on the bar was attached to one of the $\mathrm{H}$-beam (see the test setup in EIGawady and Dawood, 2012). During this experiment, when the applied load was increased, the interface joint at the bottom of the pier opened. This loading sequence stopped once the actuator reached its displacement capacity, when the specimen reached a lateral drift angle of $15 \%$ and showed the lateral strength of $17 \mathrm{kN}$. The tested tubes showed maximum tensile stress of $275.79 \mathrm{MPa}$ and modulus of elasticity of $24,821 \mathrm{MPa}$.

\section{Pile specimens subjected to vertical loads}

By studying this effort of the foreign researchers, the behavior of such pile piers made of composite materials was clarified. Fellow workers of the Department of Roads, Bridges and Tunnels at the Saint Petersburg State University of Architecture and Civil Engineering carried out tests of the piles made from fiberglass. These piles are manufactured by the method of dual helical winding. The angle between fibers equals to $55^{\circ}$. Four piles with welded metal screw caps were screwed in ground by drilling machine with maximal torque of $5200 \mathrm{kgf} / \mathrm{m}^{2}$. 


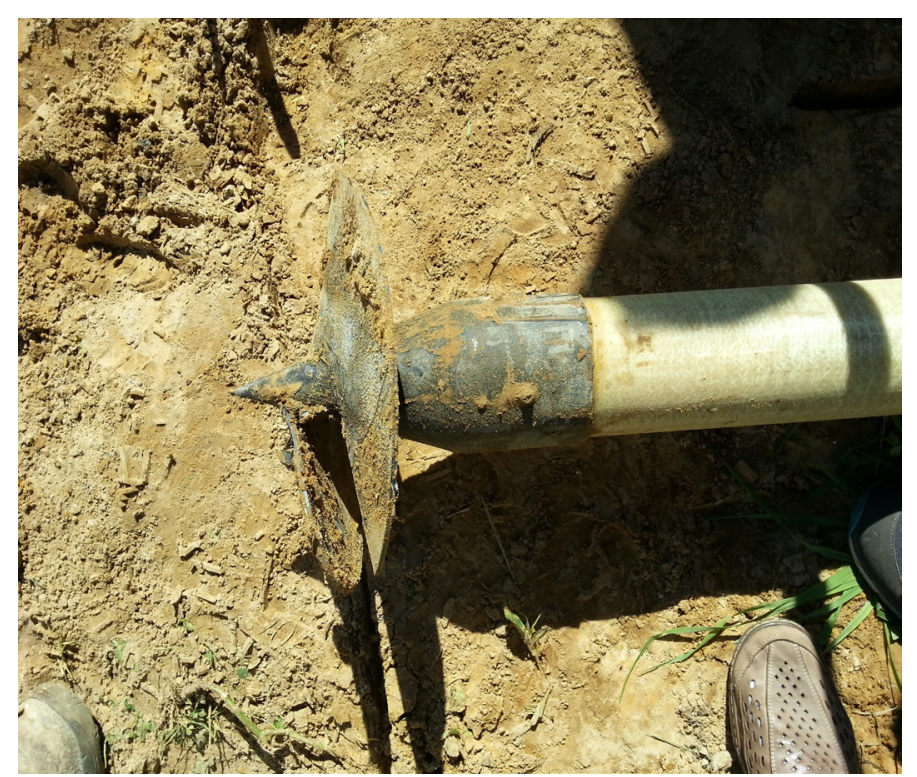

Figure 5. Composite screw pile

For the testing of composite screw piles we used dismountable setup consisting of metal $\mathrm{H}$-beam No. 30 welded to metal screw piles. In order to increase the weight, $\mathrm{H}$-beam was additionally loaded with $1.0 \mathrm{t}$ load (Figure 6). Such test setup was mounted over each composite screw pile.

After the preparatory phase, when the physical and mechanical characteristics of soil at testing ground were examined (to ensure the accurateness of the readings) and the test setup mounted, we proceeded to the first phase of tests and conducted two series of experiments. We examined bearing load of each composite screw pile and value of soil sagging under static load. At first series we increased the load stepwise by $1000 \mathrm{~kg}$. Each step was maintained at least 5 minutes. Maximal load on one composite screw pile was $11000 \mathrm{~kg}$, when the pulling out of the metal screw piles of the test setup was observed. Displacement limits for the composite piles comprised $52 \mathrm{~mm}$ and $44 \mathrm{~mm}$.

At the second series of tests, each pile was loaded with $10500 \mathrm{~kg}$ at once and then fully unloaded in order to examine the character of residual deformation. We examined bearing load of composite screw pile and value of soil sagging under cyclic load. Loading and unloading was performed in fast pace. Each cycle of loading/unloading took 2 ...3 minutes. At last cycles of loading sag-

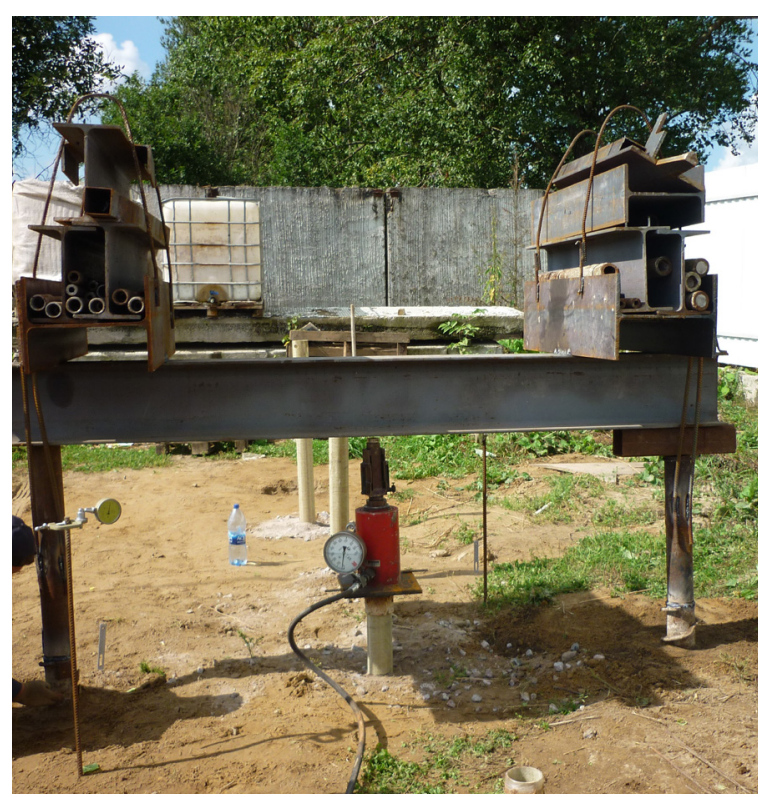

Figure 6. Overall view of the test setup

ging increase was less than $0.1 \mathrm{~mm}$, additional sagging under cyclic loading of piles for the first and the second series of tests was $18 \mathrm{~mm}$ and $15 \mathrm{~mm}$ correspondingly (or $34 \%$ of the maximum sagging value obtained during the first phase of tests).

Upon completion of the on-site tests the piles were dug out and examined in order to find possible deformations. Metal caps and joints between pultruded fiberglass tube and metal caps have not deformed.

\section{Conclusions}

The results of this experiment led to the conclusion: composite screw piles worked well when tested on static and cyclic compressive load. Bearing of 11 tons loading by a $100 \mathrm{~mm}$ diameter pile with screw cap having $400 \mathrm{~mm}$ diameter blade is well enough to recommend the use of such piles in the construction, including the construction of transport facilities. This type of structures may in principle be applied as structural components of pile piers of small bridges. In order to identify the properties of the structures, we will continue experiments examining bearing horizontal loads and pull-out behavior. Introduction of composite structures to the Russian bridge engineering is not just possible, but inevitable due to certain advantages of composites over traditional materials.

\section{References}

EIGawady, M., Dawood, M. (2012). Analysis of Segmental Piers Consisted of Concrete Filled FRP Tubes. Engineering Structures, 38(2012), pp. 142-152.

Ivanchev, I. (2008). Reinforced Concrete Road Bridges [Zhelezobetonnye avtodorozhnye mosty]. Saint Petersburg: Izdatel'stvo Assotsiatsii stroitel'nykh vuzov (in Russian).

Salamakhin, P. (ed.) (2014). Engineering Structures In Transport Construction [Inzhenernye sooruzheniya v transportnom stroitel'stve]. Vol. 2. Moscow: Akademiya (in Russian).

Solntsev, Yu. (ed.) (2007). Material Engineering. Application and Selection of Materials [Materialovedenie. Primenenie $i$ vybor materialov]. Saint Petersburg: Khimizdat (in Russian). 